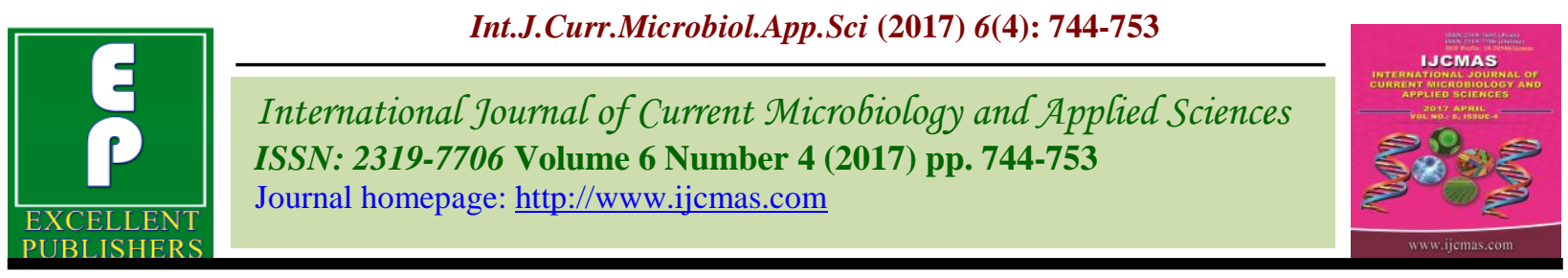

Original Research Article https://doi.org/10.20546/ijcmas.2017.604.092

\title{
Assessing Stress Tolerant Rhizobial Isolates of Clusterbean (Cymopsis tetragonoloba (L.) Taub.) Retrieved from Semi- Arid Regions of Haryana, India
}

\author{
Subha Dhull* and Rajesh Gera
}

Department of Microbiology, CCS Haryana Agricultural University, Hisar-125004, India

*Corresponding author

\begin{tabular}{|c|c|}
\hline & A B S T R A C T \\
\hline & \multirow{8}{*}{$\begin{array}{l}\text { An attempt has been made to evaluate the effect of abiotic constraints (drought and } \\
\text { temperature) on the growth of rhizobia isolated from clusterbean grown in semiarid } \\
\text { regions of Haryana with a view to screen out stress tolerant rhizobial isolates. A total of } \\
158 \text { rhizobial isolates have been used for screening their stress tolerating ability with } \\
\text { contrast to environmental abiotic soil conditions commonly prevailing in semi-arid regions } \\
\text { of Haryana. All the isolates were phenotypically and biochemically characterized. Growth } \\
\text { of pure rhizobial isolates on Yeast Extract Mannitol Agar (YEMA) medium having } \\
\text { variable range of temperature ( } 30,35,40 \text { and } 45 \text { ) and different concentrations of PEG ( } 0 \text {, } \\
10,20,30,40 \text { and } 50 \% \text { ) were recorded at } 420 \mathrm{~nm} \text { using UV-VIS spectrophotometer after } \\
\text { incubation at } 30 \circ \mathrm{C} \text { for five days. On the basis of comparison of growth under varied stress } \\
\text { conditions, fifty four rhizobial isolates from combined (temperature as well as drought) } \\
\text { stress study were screened out. The stress tolerant traits of these rhizobia are of potential } \\
\text { value from the point of view of biofertilization of legume seedlings during a forestation of } \\
\text { degraded areas in semi-arid tropics of Haryana. }\end{array}$} \\
\hline Keywords & \\
\hline $\begin{array}{l}\text { Rhizobia, } \\
\text { Clusterbean, }\end{array}$ & \\
\hline $\begin{array}{l}\text { Drought tolerance, } \\
\text { PEG. }\end{array}$ & \\
\hline Article Info & \\
\hline $\begin{array}{l}\text { Accepted: } \\
\text { 06 March } 2017\end{array}$ & \\
\hline Available Online: & \\
\hline 10 April 2017 & \\
\hline
\end{tabular}

\section{Introduction}

India and Pakistan are the main producers of clusterbean which accounting for $80 \%$ production of the world's total, while Haryana and Rajasthan occupies the largest area $(82.1 \%)$ in India (Pathak et al., 2010). In India, 3.34 million hectares of the farmable land was under guar cultivation during the year 2006-2007 (Ministry of Agri. and Co-op GOI, 2010). It is cultivated in arid zones of Rajasthan, some arid and semi-arid regions of Haryana and Madhya Pradesh. The productivity of guar ranges from $474 \mathrm{~kg} / \mathrm{ha}$ in Rajasthan to $1200 \mathrm{~kg} / \mathrm{ha}$ in Haryana. In the recent years, clusterbean cultivation has become an attractive option with the farmers due to availability of high yielding varieties with high gum (30 to $35 \%$ of whole seed) content (galactomannans) in its endosperm which has great value as an enhancer of viscosity in food industry, like whipped cream substitutes a stabilizer for cheese, stiffner in soft ice-cream and instant pudding and as a metal binder. It is widely used from cosmetic and paper to mining and explosive industry (Whistler and Hymowitz, 1979; Mudgil et al., 2014). Like other legumes, clusterbean is nodulated by Rhizobium or Bradyrhizobium strains belonging to cowpea miscellany group. Though, legume-Rhizobium symbiosis has been extensively studies in many crops 
but despite of its multipurpose use, no systematic work has been done to exploit the nitrogen-fixing ability of this crop and for increasing its production. Poor nodulation of clusterbean (guar) in Haryana may be due to environmental conditions such as high temperature and drought conditions. The poor survival of the inoculated culture and low density of rhizobial population in the field soil may also result in poor noduation of this crop. Since an adequate number of effective nodules can provide all the nitrogen requirement of this crop but it is desirable to have Rhizobium strains that would effectively nodulate cluster bean and fix nitrogen under agroclimatic conditions of Haryana.

Drought stress is one of the major limitations to crop productivity. It is the most common stress affecting plant growth in arid and semiarid regions. Thus, it is necessary to improve the level of efficiency in plant capture and use of water and nutrients. Inoculation of plants with native beneficial microorganisms may increase drought tolerance of plants growing in arid or semi-arid areas (Marulanda et al., 2007). Abiotic stress tolerance in soil microorganisms has been studied to provide a biological understanding of the adaptation and survival of living microorganisms in extreme environments. Shortage of water compromises plant and rhizobial growth and is a major cause of nodulation failure and low $\mathrm{N}_{2}$ fixation. Water stress affects rhizobial morphology, survival, growth and population structure in soil (Guerin et al., 1991). Symbiotic $\mathrm{N}_{2}$ fixation of legumes is also highly sensitive to soil water deficiency. A number of temperate, tropical and shrub legumes exhibit a reduction in nitrogen fixation when subjected to soil moisture deficit. This is due to the fact that water stress affects the formation and longevity of nodules, synthesis of leghaemoglobin and nodule function (Guerin et al., 1991). In general, the wide range of moisture levels characteristic of ecosystems where legumes have been shown to fix nitrogen suggests that rhizobial strains with different sensitivity to soil moisture can be selected. Studies have shown that sensitivity to moisture stress varies for a variety of rhizobial strains. Thus, it can be assumed that rhizobial strains can be selected with moisture stress tolerance within the range of their legume host. The modification of rhizobial cells by water stress will eventually lead to a reduction in infection and nodulation of legumes (Zahran, 1999). Optimization of soil moisture for growth of the host plant, which is more sensitive to moisture stress than bacteria, results in maximal development of fixed-nitrogen inputs into the soil system by the legumeRhizobium symbiosis (Tate, 1995), the clusterbean crop growing environment in the Semi-Arid Tropics (SAT) is highly variable due to erratic spacing and timing of season rainfall. Therefore, this legume grown under semi-arid lands require temperature and drought tolerant rhizobia for effective symbiosis (Singh et al., 1999). The present study aimed to isolate temperature and drought tolerant Rhizobia that nodulate clusterbean crop under high temperature and drought conditions.

\section{Materials and Methods}

\section{Collection of root nodules and isolation of rhizobia}

Sixty seven soil samples were collected from Bhiwani, Hisar and Mahendergarh districts of Haryana. The seeds of clusterbean variety HG-563 were sown in 67 pots containing $2 \mathrm{~kg}$ of each soil sample and each pot was containing 3 or 4 clusterbean plants. All the pots supported the growth of clusterbean plants and the nodule formation was observed in all pots. After 45 days of growth, when nodule formation took place on the roots of clusterbean plants, 2 or 3 healthy pink 
nodules were collected from each plant and surface sterilized by using $0.1 \% \mathrm{HgCl}_{2}$ and ethanol as described in material and methods section.

The nodules were crushed and streaked on Yeast extract Mannitol medium (YEMA) medium plates containing Congo red dye. The colonies from each nodule were purified by streaking 2-3 times on same media. In total 158 rhizobial isolates were obtained, out of which 92 isolates obtained from Bhiwani, 30 and 36 isolates from Hisar and Mahendergarh, respectively. Pure cultures were obtained with one or more further sub-culturing steps. These rhizobial isolates were further purified and maintained on YEMA slants and were stored at $4{ }^{0} \mathrm{C}$ on slants for further studies.

\section{Authentication of rhizobia by plant} infectivity test

All the 158 rhizobial isolates were authenticated by plant infection test using clusterbean seeds (HG-563) under sterilized conditions in coffee cups (Giri and Dudeja, 2013). Seeds were surface-sterilized with a $0.2 \% \mathrm{HgCl}_{2}$ followed by $70 \%$ ethanol and finally rinsed in five changes of sterile water. Sterilized seeds were inoculated with $\log$ phase growing rhizobial cultures $\left(10^{4}-10^{5}\right.$ cfu/seed) and sown in sterilized coffee cups containing sand in triplicate. Seedlings were watered with sterilized tap water. Nodule formation was scored after 45 days.

\section{Stress tolerance studies}

A total 158 clusterbean rhizobial isolates were screened for abiotic stress tolerance particularly drought tolerance with respect to 0, 10, 20, 30, 40 and 50\% polyethylene glycol (PEG) and temperature tolerance on YEMA medium plates at $30,35,40$ and $45{ }^{\circ} \mathrm{C}$ in BOD incubator.

\section{Determination of temperature tolerance rhizobia}

The effect of temperature on rhizobia-growth was studied using different temperature. Ten microliters of YEM overnight culture was spotted on YEMA medium plates, after incubation at 30, 35, 40 and 450C. After 5 days of incubation, rhizobial growth was recorded by visual observation compared to control treatments incubated at $30^{\circ} \mathrm{C}$.

\section{Determination of drought tolerance rhizobia}

The effect of drought on rhizobia-growth was studied using polyethylene glycol (PEG) 6000. One hundred microliters of YEM overnight culture was transferred to $10 \mathrm{ml}$ of the same YM broth supplemented with 10, 20, 30,40 and $50 \%$ PEG, after incubation at $30^{\circ} \mathrm{C}$ with shaking at $120 \mathrm{rpm}$ for five days the bacterial growth was measured spectrophotometrically The growth was measured spectrophotometrically at OD 420 nm (Abdel-salam et al., 2011).

\section{Determination of combined stress tolerance rhizobia}

The YEM broth supplemented with 20, 30 and $40 \%$ polyethylene glycol (PEG) concentration were prepared. Log phase grown culture was inoculated in YEM broth supplemented with different concentration polyethylene glycol (PEG).

The broth were incubated at 40 or $45^{\circ} \mathrm{C}$ depending upon the highest PEG concentration and temperature tolerance of the individual isolate during single stress.

The growth was measured spectrophotometrically at OD $420 \mathrm{~nm}$ (Abdelsalam et al., 2011). 


\section{Results and Discussion}

\section{Isolation and authentication of rhizobia}

A total of 158 rhizobial isolates obtained from different nodules were characterized by using Gram staining and peptone water test. It was observed that all the isolates were found to be Gram negative with small rods. Moreover, the isolates obtained from same soil samples showed identical cell shape and size. For peptone water test, all the isolates were inoculated in test tubes containing $5 \mathrm{ml}$ peptone water broth and incubated at $30^{\circ} \mathrm{C}$ for 3-4 days to observe the growth of the isolates. Most of the rhizobial isolates did not show the growth in peptone water broth with control, however, only a few were able to grow in the above broth indicating the doubt about its authenticity. Thus, on the basis of Gram staining and peptone water test, 158 rhizobial isolates were selected for abiotic stress tolerance.

Table.1 Number of cluster bean rhiobial isolates obtained from different districts along with their isolates number

\begin{tabular}{|c|c|c|c|}
\hline $\begin{array}{l}\text { S. } \\
\text { No. }\end{array}$ & District & Rhizobial isolates number & $\begin{array}{l}\text { No. of } \\
\text { isolates }\end{array}$ \\
\hline 1 & Bhiwani & $\begin{array}{l}\text { GB-1a, GB-1b, GB-1c, GB-2a, GB-2b, GB-3a, GB-4a, GB- } \\
\text { 5a, GB-5-b, GB-5c, GB-7a, GB-7b, GB-8a, GB-8b, GB-9a, } \\
\text { GB-10a, GB-10b, GB-10c, GB-10d, GB-11a, GB-11b, GB- } \\
\text { 11c, GB-12a, GB-12b, GB-13a, GB-14a, GB-14b, GB-14c, } \\
\text { GB-15a, GB-16a, GB-16b, GB-16c, GB-16d, GB-17a, GB- } \\
\text { 17b, GB-17c, GB-17d, GB-18a, GB-18b, GB-19a, GB-19b, } \\
\text { GB-20a, GB-21a, GB-22b, GB-22c, GB-23a, GB-23b, GB- } \\
\text { 23c, GB-24a, GB-24b, GB-25a, GB-25b, GB-25c, GB-25d, } \\
\text { GB-26a, GB-26b, GB-26c, GB-26d, GB-26e, GB-27a, GB- } \\
\text { 27b, GB-27c, GB-27d, GB-28a, GB-28b, GB-28c, GB-29a, } \\
\text { GB-29b, GB-29c, GB-30a, GB-30b, GB-31a, GB-31b, GB- } \\
\text { 32a, GB-32b, GB-32c, GB-32d, GB-33a, GB-33b, GB-33c, } \\
\text { GB-34a, GB-35a, GB-35b, GB-35c, GB-36a, GB-36b, GB- } \\
\text { 38a, GB-38b, GB-38c, GB-39a, GB-39b, GB-39c }\end{array}$ & 92 \\
\hline 2 & Hisar & $\begin{array}{l}\text { GH-1a, GH-1b, GH-1c, GH-1d, GH-2a, GH-2b, GH-2c, GH- } \\
\text { 3a, GH-4a, GH-4b, GH-4c, GH-4d, GH-5a, GH-5b, GH-5c, } \\
\text { GH-5d, GH-6a, GH-6b, GH-6c, GH-6d, GH-7a, GH-7b, GH- } \\
\text { 7c, GH-7d, GH-8a, GH-8b, GH-9a, GH-9b, GH-9c, GH-9d }\end{array}$ & 30 \\
\hline 3 & Mahendergarh & $\begin{array}{l}\text { GM-1a, GM-2a, GM-2b, GM-3a, GM-3b, GM-3c, GM-4a, } \\
\text { GM-5a, GM-5b, GM-6a, GM-7a, GM-7b, GM-7c, GM-8a, } \\
\text { GM-9a, GM-9b, GM-9c, GM-10a, GM-11a, GM-11b, GM- } \\
\text { 11c, GM-12a, GM-13a, GM-13b, GM-13c, GM-14a, GM- } \\
\text { 14b, GM-14c, GM-14d, GM-15a, GM-15b, GM-15c, GM- } \\
\text { 16a, GM-16b, GM-16c, GM-16c, GM-16d }\end{array}$ & 36 \\
\hline & & Total & 158 \\
\hline
\end{tabular}


Table.2 Effect of temperature as well as drought on the growth of rhizobial isolates

\begin{tabular}{|c|c|c|c|c|}
\hline \multirow{3}{*}{$\begin{array}{l}\text { S. } \\
\text { No. }\end{array}$} & \multirow{3}{*}{$\begin{array}{l}\text { Rhizobial } \\
\text { isolates }\end{array}$} & \multicolumn{2}{|c|}{$40^{\circ} \mathrm{C}$} & \multirow{2}{*}{$\frac{45^{\circ} \mathrm{C}}{\text { PEG concentration }(\%)}$} \\
\hline & & \multicolumn{2}{|c|}{ PEG concentration (\%) } & \\
\hline & & 40 & 30 & 20 \\
\hline 1 & GB-1a & ND & 0.028 & ND \\
\hline 2 & GB-1b & ND & 0.129 & ND \\
\hline 3 & GB-3a & ND & 0.089 & ND \\
\hline 4 & GB-5c & ND & $\mathrm{ND}$ & - \\
\hline 5 & GB-7a & ND & 0.054 & ND \\
\hline 6 & GB-10b & $\mathrm{ND}$ & 0.008 & ND \\
\hline 7 & GB-10c & ND & 0.066 & ND \\
\hline 8 & GB-14a & ND & 0.012 & ND \\
\hline 9 & GB-14c & $\mathrm{ND}$ & 0.194 & 0.103 \\
\hline 10 & GB-16a & ND & 0.161 & - \\
\hline 11 & GB-17a & ND & 0.085 & ND \\
\hline 12 & GB-18b & 0.099 & 0.181 & $\mathrm{ND}$ \\
\hline 13 & GB-19b & ND & 0.111 & ND \\
\hline 14 & GB-24b & ND & $\mathrm{ND}$ & 0.064 \\
\hline 15 & GB-25d & ND & 0.016 & ND \\
\hline 16 & GB-26b & $\mathrm{ND}$ & 0.078 & ND \\
\hline 17 & GB-26d & 0.132 & $\mathrm{ND}$ & 0.155 \\
\hline 18 & GB-27b & ND & 0.029 & ND \\
\hline 19 & GB-29a & ND & ND & 0.131 \\
\hline 20 & GB-30a & ND & 0.118 & ND \\
\hline 21 & GB-31b & ND & 0.065 & ND \\
\hline 22 & GB-32a & ND & 0.046 & - \\
\hline 23 & GB-32c & 0.071 & 0.116 & 0.080 \\
\hline 24 & GB-32d & ND & 0.024 & 0.052 \\
\hline 25 & GB-36b & ND & 0.143 & ND \\
\hline 26 & GB-38b & ND & 0.099 & 0.007 \\
\hline 27 & GH-1a & ND & ND & - \\
\hline 28 & $\mathrm{GH}-2 \mathrm{~b}$ & ND & 0.107 & ND \\
\hline 29 & GH-2c & ND & 0.031 & ND \\
\hline 30 & $\mathrm{GH}-4 \mathrm{~b}$ & ND & 0.051 & 0.042 \\
\hline 31 & GH-4d & ND & ND & - \\
\hline 32 & GH-5a & $\mathrm{ND}$ & 0.145 & ND \\
\hline 33 & GH-5b & 0.122 & ND & ND \\
\hline 34 & GH-5d & ND & 0.036 & ND \\
\hline 35 & GH-6d & $\mathrm{ND}$ & 0.111 & $\mathrm{ND}$ \\
\hline 36 & GH-7d & 0.067 & 0.080 & ND \\
\hline
\end{tabular}




\begin{tabular}{|c|c|c|c|c|}
\hline 37 & GH-8a & 0.086 & 0.100 & ND \\
\hline 38 & GH-9a & ND & 0.044 & ND \\
\hline 39 & GH-9b & ND & 0.106 & $\mathrm{ND}$ \\
\hline 40 & GM-1a & ND & 0.002 & $\mathrm{ND}$ \\
\hline 41 & GM-3c & 0.142 & ND & ND \\
\hline 42 & GM-5a & 0.064 & 0.092 & 0.052 \\
\hline 43 & GM-6a & ND & 0.038 & $\mathrm{ND}$ \\
\hline 44 & GM-7c & $\mathrm{ND}$ & 0.003 & - \\
\hline 45 & GM-8a & $\mathrm{ND}$ & $\mathrm{ND}$ & $\overline{\mathrm{ND}}$ \\
\hline 46 & GM-10a & $\mathrm{ND}$ & 0.101 & 0.041 \\
\hline 47 & GM-11b & $\mathrm{ND}$ & 0.099 & 0.058 \\
\hline 48 & GM-11c & ND & 0.024 & ND \\
\hline 49 & GM-13a & ND & 0.131 & ND \\
\hline 50 & GM-14b & ND & 0.088 & ND \\
\hline 51 & GM-14c & ND & $\mathrm{ND}$ & - \\
\hline 52 & GM-15b & ND & ND & - \\
\hline 53 & GM-15c & ND & ND & 0.070 \\
\hline 54 & GM-16b & ND & $\mathrm{ND}$ & $\mathrm{ND}$ \\
\hline
\end{tabular}

Fig.1 Isolation of rhizobia nodulating cluster bean using trap plants from different districts of south-western Haryana
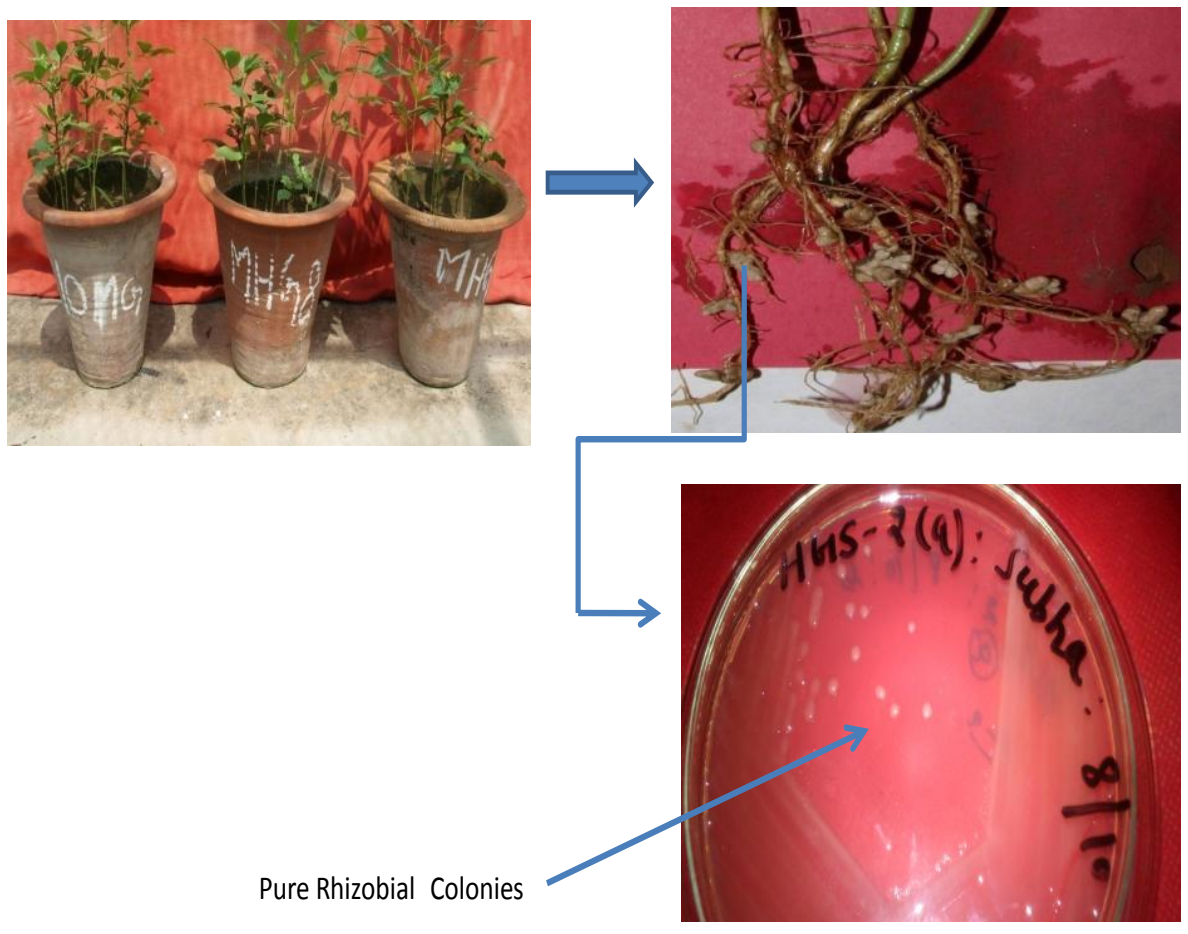
Fig.2 Morphological characterization of cluster bean rhizobial isolates using Gram staining and peptone water test

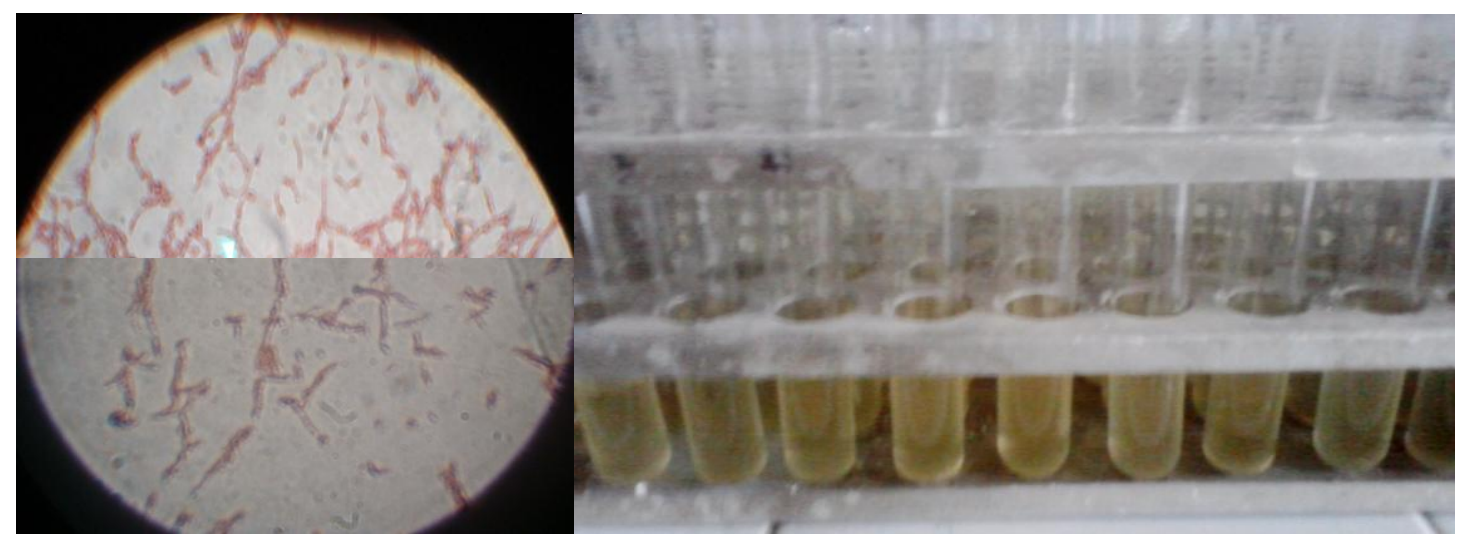

Fig.3 Combined (drought and temperature) stress tolerance by cluster bean rhizobial isolates

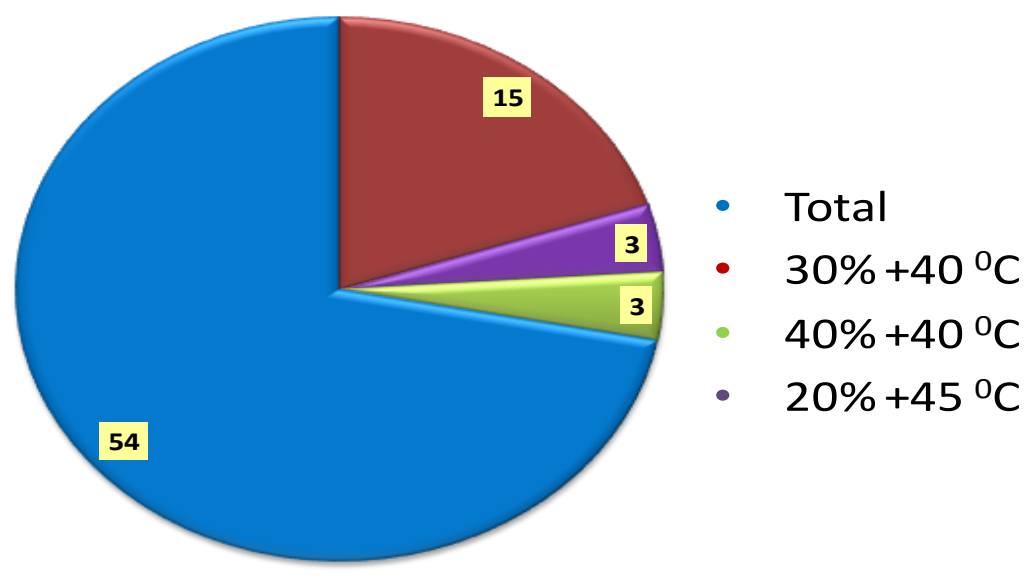

Fig.4 Temperature tolerance by cluster bean rhizobial isolates

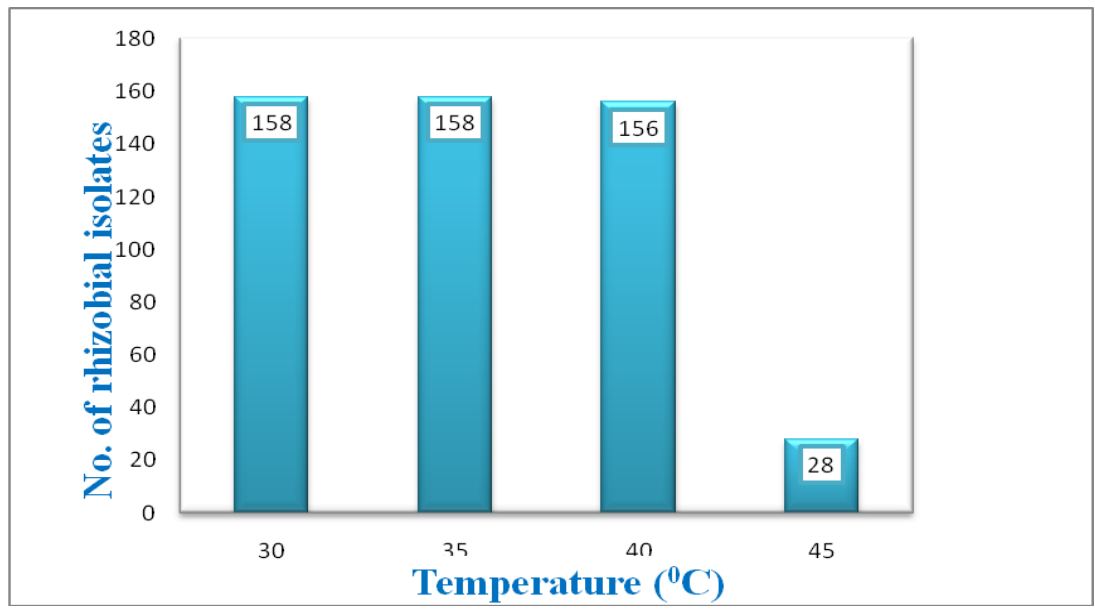


Fig.5 Drought tolerance by cluster bean rhizobial isolates

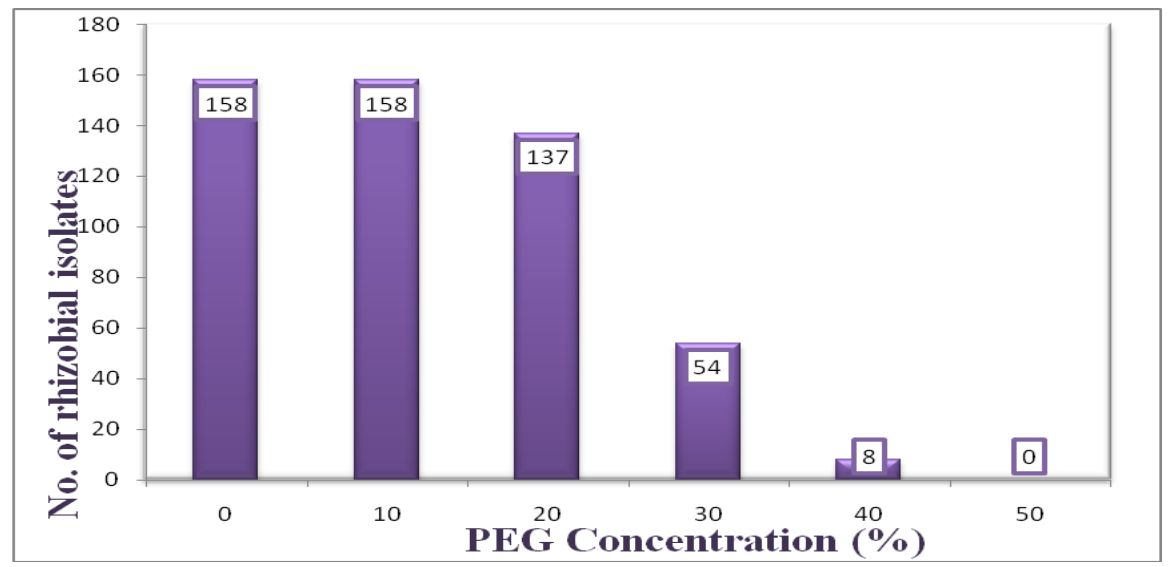

\section{Temperature tolerance}

In general, majority of the isolates exhibited luxuriant growth at the temperature ranging from $25^{\circ} \mathrm{C}-35^{\circ} \mathrm{C}$. In present study, it was observed that all the rhizobial isolates were able to grow at temperatures i.e. $30,35^{\circ} \mathrm{C}$. However, 156 rhizobial isolates showed growth at $40^{\circ} \mathrm{C}$, except few isolates where growth was slightly suppressed, while only 28 were able to grow at $45^{\circ} \mathrm{C}$, out of which some showed good, moderate and poor growth. Further increase in temperature led to noticeable decline in growth. These findings agreed with the results of previous studies on Rhizobium leguminosarum strains isolated from Nile Valley of Egypt which showed tolerance to temperatures ranging between 35$40^{\circ} \mathrm{C}$ (Moawad and Beck, 1991) and Cicer arietinum rhizobial isolates, which grew at $45^{\circ} \mathrm{C}$ (Maatallah et al., 2002). Ours results are also agreement with that of Graham (1992) who reported that rhizobia can grow better from 10 to $37^{\circ} \mathrm{C}$ and maximum temperature for growth in free-living rhizobia ranged between $35-45^{\circ} \mathrm{C}$ (Zhang et al., 1991; Zahran et al., 1994). However, Kulkarni et al., 2000 observed survival of rhizobial strains from Sesbania aculaeta at 50 and $65^{\circ} \mathrm{C}$ on YEMA plates at $\mathrm{pH} 7.0$ for up to 2 and 4 hours.

\section{Drought tolerance}

In the present study rhizobial strains growth were measured after their exposure to $10 \%$ to 50\% PEG 6000, for five days (Fig. 5). Tolerance to drought stress is a very complex phenotype that involves not only the bacterial ability to tolerate the stress but also the swiftness to respond and adapt to the environmental change. In the current study, decreased growth of rhizobial isolates with increasing PEG concentration was registered. As much as $60 \%$ of legume production in the developing world occurs under conditions of significant drought stress (Graham and Vance, 2003; Zhang et al., 2007). The effect of drought on rhizobia-growth was studied using polyethylene glycol (PEG) 6000. So all the rhizobial isolates were tested for drought tolerance in YEM broth supplemented with 0, 10, 20, 30, 40 and 50\% PEG. Most of the rhizobial isolates were able to grow up to 20\% PEG, however, there was drastic decrease in their growth rate with increasing concentration of PEG. Out of 158 rhizobial isolates, only 54 and 8 isolates were able to grow at 30 and $40 \%$ PEG, respectively and none of them was able to grow at 50\% PEG concentration. (Fig.5). Uma et al., (2013) studied 30 isolates using YEM broth supplemented with PEG. All the 30 isolates grew well in YEM broth without PEG. As the 
concentration of PEG increased, the growth was found to decrease. The isolates SBJ-2, SBJ-10, SBJ-14 and SBJ-23 were found to grow at $30 \%$ PEG 6000 . These results are conformity with the results of Abdel-Salam et al., 2011. The growth and persistence of Rhizobia and Bradyrhizobia in soils are negatively impacted by drought conditions (Cytryn et al., 2007).

\section{Combines stress (temperature as well as drought) tolerance}

All the selected abiotic stress tolerant clusterbean rhizobial isolates were also tested for combined stress tolerance i.e. drought as well as temperature. In the presence of combined stress, out of 54 clusterbean rhizobial isolates, 15 were able to grow in presence of $30 \%$ PEG at $40^{\circ} \mathrm{C}$, whereas 3 and 3 clusterbean rhizobial isolates were able to grow in presence of $40 \%$ PEG at $40^{\circ} \mathrm{C}$ and 20\% PEG at $45^{\circ} \mathrm{C}$, respectively (Fig. 3). This study showed that there was considerable variability in the level of stress tolerance of rhizobial isolates obtained from clusterbean plants native to semi-arid regions of Haryana. Based upon the comparative assessment, we have screened three isolates from combined stress tolerant study i.e. high temperature as well as drought (GB-14c, GB-26d and GB$32 \mathrm{c}$ which could further be utilized for their symbiotic effectiveness determination under field conditions in semi-arid regions of Haryana.

\section{Acknowledgement}

We thank the Department of Microbiology, CCS Haryana Agricultural University, Hisar, India for providing necessary facilities for this work.

\section{References}

Abdel-Salam, M.S., S.A. Ibrahim, M.M. AbdEl- Halim, F.M. Badanwy and Abu-
Aba, S.E.M. 2010. Phenotypic characterization of indigenous Egyptian Rhizobial strains for abiotic stresses performance. J. Amer. Sci., 619: 498503.

Cytryn, E.J., Sangurdekar, D.P., Streeter, J.G., Franck, W.L., Chang, W.S., Stacey, G., Emerich, D.W., Joshi, T., Xu, D. and Sadowsky, M.J. 2007. Transcriptional and physiological responses of Bradyrhizobium japonicum to desiccation induced stress. J. Bacteriol., 189: 6751-6762.

Graham, P.H. 1992. Stress tolerance in Rhizobium and Bradyrhizobium and nodulation under adverse soil conditions. Can. J. Microbiol., 38: 475484.

Graham, P.H. and Vance, C.P. 2003. Legumes: Importance and constraints to greater use. Plant Physiol., 131: 872877.

Guerin, V., Trinchant, J.C. and Rigaud, J. 1991. Nitrogen fixation (C2H2) reduction by broad bean (Vicia faba L.) nodules and bacteriods under water restricted conditions. Plant Physiol., 92: 595-601.

Kulkarni, S., Surange, S. and Nautiyal, C.S. 2000. Crossing the limits of Rhizobium existence in extreme conditions. $J$. Curr. Microbiol., 41: 402-409.

Maatallah, J., Berraho, E., Sanjuan, J. and Lluch, C. 2002. Phenotypic characterization of rhizobia isolated from chickpea (Cicer arietinum) growing in Moroccoan soils. Agronomie, 22: 321329.

Marulanda, A., Porcel, R., Barea, J. M. and Azcon, R. 2007. Drought tolerance and antioxidant activities in lavender plants colonized by native drought-tolerant or drought-sensitive Glomus sp. Microbol. Ecol., 54: 543-552.

Moawad, H., and Beck, D.P. 1991. Some characteristics of Rhizobium 
leguminosarum isolates from uninoculated field grown lentil. Soil Biol. Biochem., 23: 933-937.

Mudgil, D., Barak, S. and Khatkar, B. 2014. Guar gum: processing, properties and food applications A Review. J. Food Sci. Technol., 51(3): 409-418.

Pathak, S. K., Singh, M. and Henry, A. 2010. Molecular assessment of genetic diversity in clusterbean (Cyamopsis tetragonoloba) genotypes. J. Genet., 89: 243-246.

Singh, S.A., M. Ramakrishna and Rao, A.G.A. 1999. Optimization of downstream processing parameters for the recovery of pectinase from the fermented broth of Aspergillus carbonarious. Process Biochem., 35: 411-417.

Tate, R.L. 1995. Soil Microbiology (Symbiotic Nitrogen Fixation. John Wiley and Sons. pp. 503-507.

Whistler, R.L. and Hymowitz, T. 1979. Guar. Agronomy, production, Industrial use and Nutrition. Purdue University press wheat Lafayette, Indiana. p. 16-28.

Zahran, H.H. 1999. Rhizobium-legume symbiosis and nitrogen fixation under severe conditions and in an arid climate. Microbiol. Mol. Biol. Rev., 63: 968-989.

Zahran, H.H., Karsisto, L.A.M. and Lindstorm, K. 1994. Alteration of lipopolysacharides and protein profiles in SDS-PAGE of rhizobia by osmotic stress. World J. Microbiol. Biotechnol., 10: 100-105.

Zhang, L.X., Li, S.X., Zhang, H. and Liang, Z.S. 2007. Nitrogen rates and water stress effects on production, lipid peroxidation and antioxidative enzyme activities in two maize (Zea mays L.) genotypes. J. Agron. Crop Sci., 11: 387397.

Zhang, X., Harper, R., Karsisto, M. and Lindstrom, K. 1991. Diversity of Rhizobium bacteria isolated from the root nodules of leguminous trees. Int. J. Syst. Bacteriol., 41: 104-113.

\section{How to cite this article:}

Subha Dhull and Rajesh Gera. 2017. Assessing Stress Tolerant Rhizobial Isolates of Clusterbean (Cymopsis tetragonoloba (L.) Taub.) Retrieved from Semi- Arid Regions of Haryana, India. Int.J.Curr.Microbiol.App.Sci. 6(4): 744-753.

doi: https://doi.org/10.20546/ijcmas.2017.604.092 